\title{
The Applied Educational Milestone of Discourse Methods and Rhetoric Etiquettes in Surat Maryam
}

\author{
Ibrahim Mustafa Othman \\ College of Islamic Sciences, Salahaddin University, Erbil, Iraq \\ ibrahimdiana1977@gmail.com
}

KEYWORDS: $\quad$ Pedagogical Methods, Dialogue, Surat Maryam, Education, Educational Milestone.

Crossref doi https://doi.org/10.51345/.v32i4.435.g251

\begin{abstract}
:
This study explores one of the most active and productive educational methods; hence, this stylistic phenomenon has its importance in embellishing discourse and speech with respect to diverse opinions. Nowadays, societies love discussions and debating especially Middle-East ones. A simple discussion may lead to a different topic and escalates into a hot debate that may be accompanied by verbal and physical conflicts rather than tolerance and the spirit of acceptance. Active dialogues and politeness in selecting words are evidences of the nations' awareness, as they are considered to be the effective methods of dialogues and the advancement of society. This paper is divided into an introduction, definitions of terms and three sections. Firstly, the dialogues in Surah Maryam. Secondly, the etiquettes of rhetoric and talks in Surah Maryam. Thirdly, the applied educational milestone from the methods of dialogue and their etiquettes in the Surah. The importance of this research shows the fact that the dialogue styles and their etiquettes are the most important pillars in the process of people's communication, and the convergence of views among opponents and disputants. The dialogue and its etiquettes provide the most appropriate conditions for conflict resolution, compromise and consensus which reflect positive influence on human relationships among community individuals. The main objective of the study is to highlight the ways to strengthen brotherhood and human cooperation. This method and its etiquettes can be also used to renounce clash and conflicts among people and community; besides, it can be a good attempt to replace those negative points with taking the best of opinions through spreading the causes of harmony, love, goodness and peace. The most important study results are: adhering the rules of a proper dialogue to change of many nowadays conflicts into a peaceful dialogue, happiness, reduce rivalry or quarrels, and removing many obstacles in front of the people and community.
\end{abstract}


معالم توبوية مستفادة من أسلوب الحوار وآداب الخطابة والكلام في سورة ميم

\author{
ابراهيم مصطفى عثمان \\ كلية العلوم الإسلامية، جامعة صلاح الدين، أربيل، العراق \\ ibrahimdiana1977@gmail.com
}

الكلمات المفتاحية | الأساليب التربوية، الحوار، سورة مريم، التربية، معالم تربوية.

Crossref doi https://doi.org/10.51345/.v32i4.435.g251

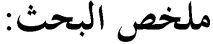

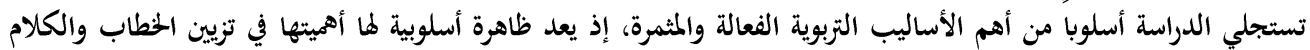

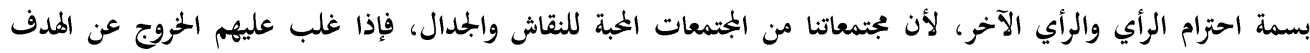

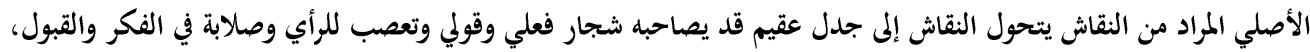

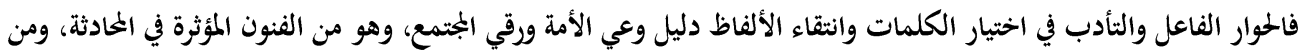

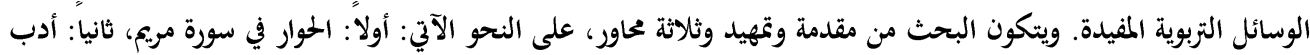

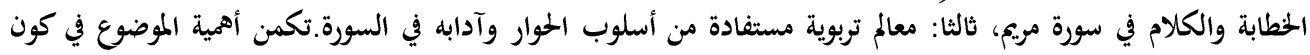

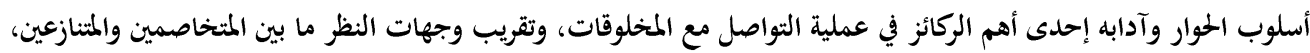

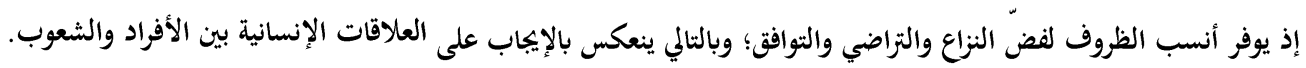

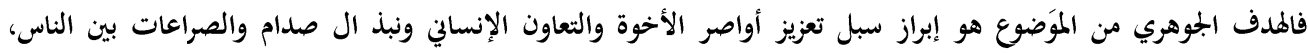

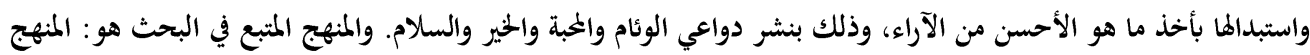

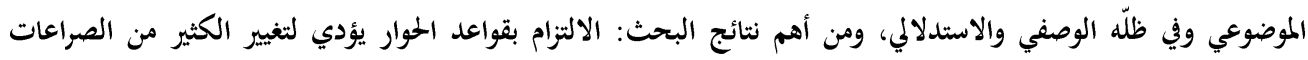

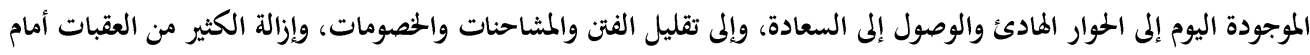

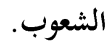

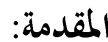

الحوار والتزام الأدب في مخاطبة الناس والتحدث إليهم من الأساليب والآداب العببة إلى النفس، حيث إنه

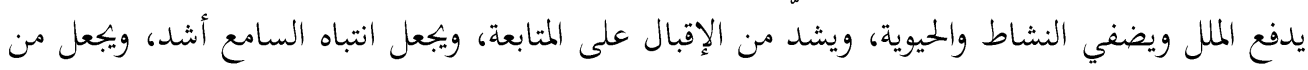

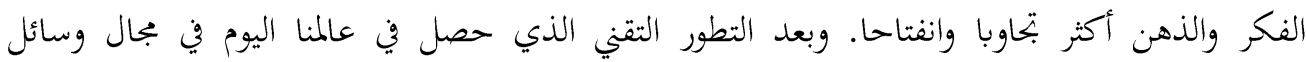
الاتصال أدى ذلك إلى أن يكون العالم مثل القرية الواحدة، بل البعض يرى أنه أصبح مثل الغرفة الواحدة،

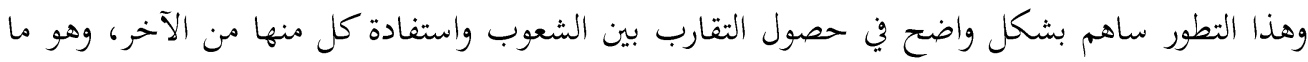


يسمى بالانفتاح الحضاري الشامل للجانب المادي والجانب الفكري والمعنوي. ولكي تستفيد الشعوب بعضها البعض، كان لا بد من حصول التفاهم والتقارب فيما بينها، وكل هذا لا يتم إلا بالحوار، لذلك ولك ولك ظهرت المناداة باستخدام لغة الحوار في نقل الحضارات للشعوب، وفي حل المشاكل والعوائق. فالقوة العسكرية وإن كانت تساهم بشكل واضح في حل بعض المشكلات وحسمها إلا أها حلول مؤقتة وضعيفة

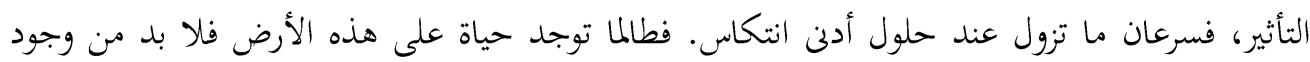

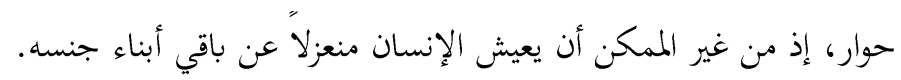

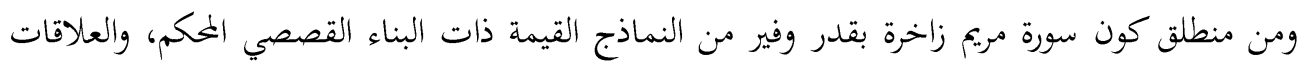

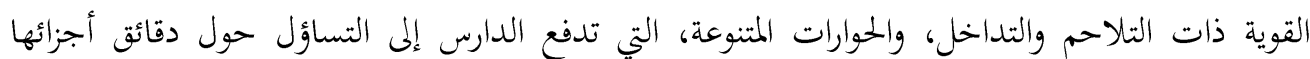
وكليات مقاطعاتما. اخترناها بين السور القرآنية، حيث سنركز عليها في هذا البحث مع بئ بيان أبرز المعالم التربوية المستفادة منها. الدراسات السابقة: هناك عدد لا بأس به من الكتب حول أسلوب الحوار وأدب الخطاب في المنهج القرآني والأحاديث النبوية الشريفة، أما بالنسبة لأسلوب الحوار في سورة مريم فقد وقفنا على كتاب (آداب الحوار

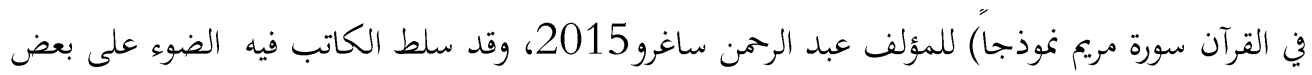
نماذج الحوار في السورة، أما موضوع استباط واستخراج المعالم والقيم التربوية من هذه الأساليب، فلم يتطرق إليه على الرغم من أهميته، لذلك سنسلط الضوء في البحث هذا بشكل دقيق على الجانب التربوي.

\section{التمهيد: بيان مفردات البحث}

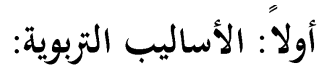

تنسجم الأساليب التربوية في القرآن الكريم مع الفطرة الإنسانية وأساليب التربية العامة، وتلبي المطالب

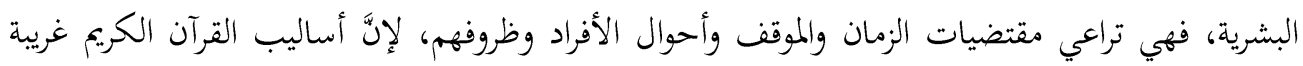

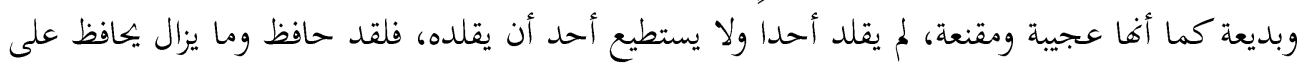

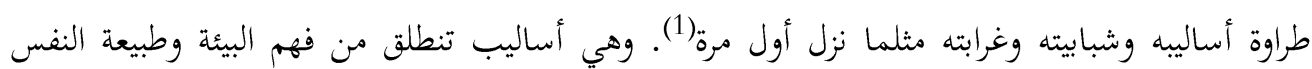

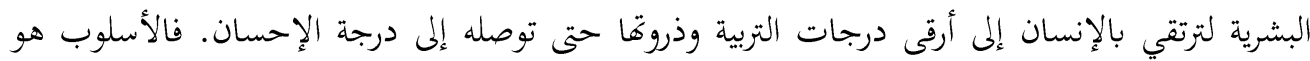

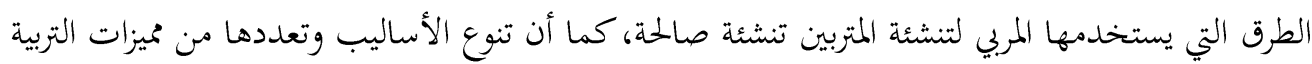
الإسلامية، حيث يتيح اختيار الأنسب للمربي والأفضل لطبيعة المتربي، بشكل يجعله يستجيب لمؤثراتها النفسية.(2) فطالما كان المخاطبون من البشر لهم طاقات وصفات بشرية، كان لا بد أن تكون الونية الوسائل 
التربوية وأساليبها بمستوى مقدرقم وتقبلهم، تتقبله النفوس وتنقاد له المشاعر. وبما أن سورة مريم اهتم

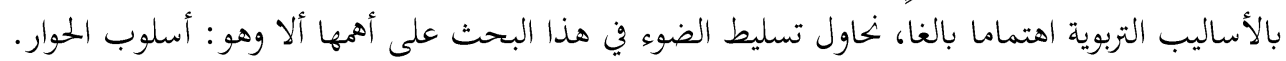

\section{ثانياً: الحوار لغةّ واصطلاحاً:}

الحوار لغة: أصل الحوار من الحور، وهو رجوع الشيء إلى شيء. بمعنى تراجع الكلام، وهم يتحاورون، أَي:

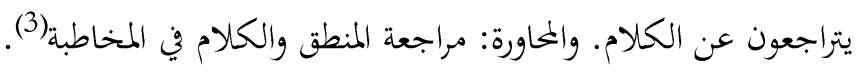

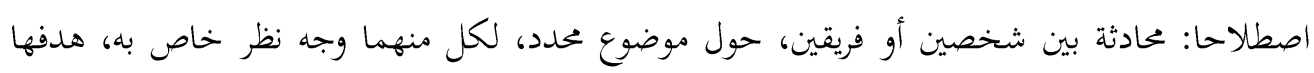

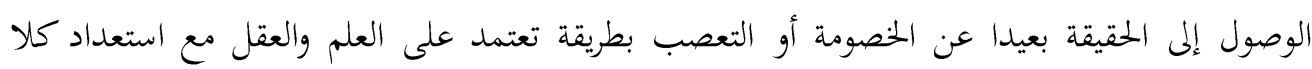

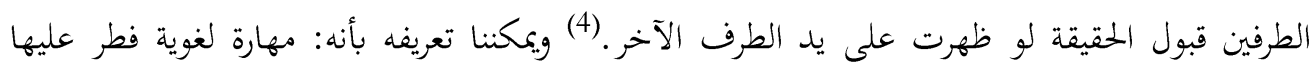
الإنسان ولا يستطيع أن يمارس حياته من دوها، وهو شكل من فئن أشكال التواصل بين جميع البشر؛ لأنه كلام واع حيث يتحمل كل متحاور مجموعة من الأفكار يسعى لإيصالها للطرف الثاني.

\section{ثالثا: سورة مريم:}

اسم السورة التوقيفي المشهور هي (مريم)، في كل المصاحف والتفاسير تقريباً(5)، وتسمية السورة باسم مريم

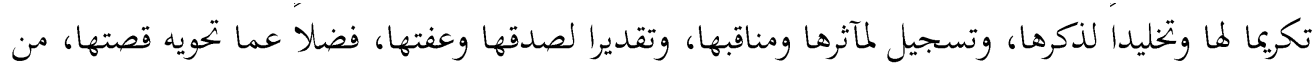

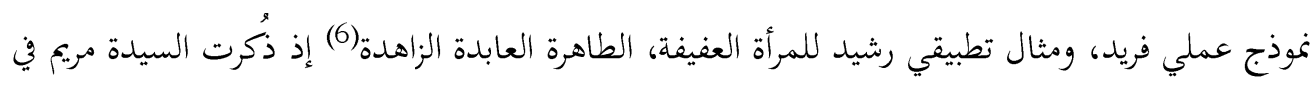

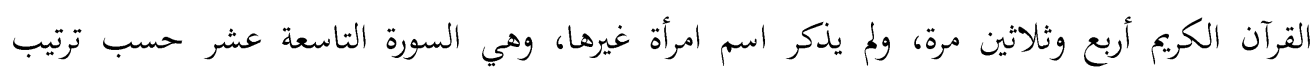

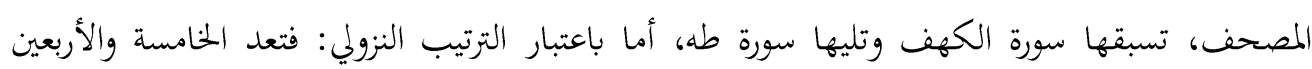
تسبقها سورة فاطر وتليها سورة طه(7). أما أبرز مقاصد السورة فيمكن إجمالها في ما يلي: إثبات وحدة الرسالة، تبرئة مريم عليها السلام، إبطال بنوة

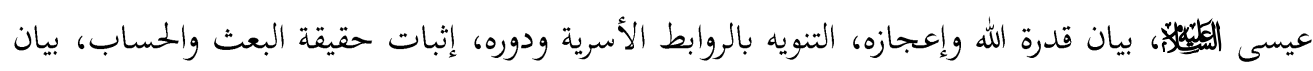
منزلة القرآن ودوره في التذكير، والدعوة إلى العمل الصالح.

\section{رابعاً: المعالم التربوية:}

بإمكاننا تلخيص المعالم التربوية بمجموعة من المفاهيم والقيم والمبادئ والمثل العليا مستفادة من نصوص كتاب الله العزيز وسنة نبيه الكريم، بالإضافة إلى الفطرة التي يكتسبها المسلم عن طريق فهمه لدينه، ينظم به به مسار

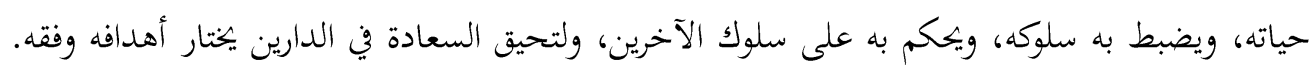

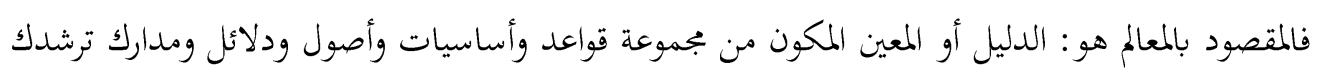


إلى التمكن من معرفة الطريق الصحيح والتميز بين السراط السوي وغيرها من السبل الضالة. فإذا كانت

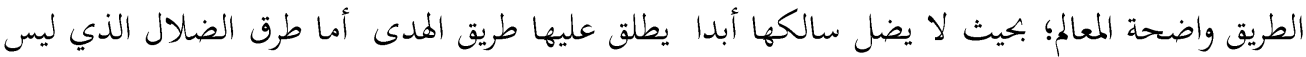

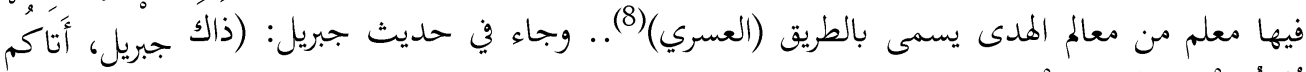

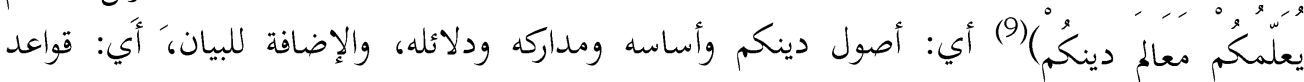
دينَكم (10)

\section{خامساً: التربية:}

التربية لغة: لفظ مشتق من الفعل ربب ورب، ربَّت الصبيَّ وربيَّهنه تربيتاً وتربية(11) رباه تربية وترباه أي غذاه

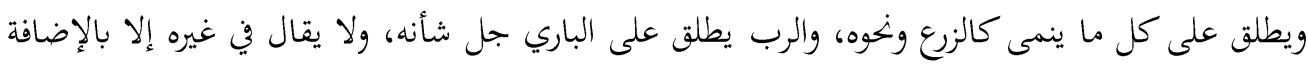
مثل ربُّ كذا(12).كما يطلق في اللغة على المالك، والسيد، والمدبر، والمربي. وللتربية دلالات لغوية متعددة: أولاً: الإصلاح، رب كلئل الشي إذا أصلحهد.

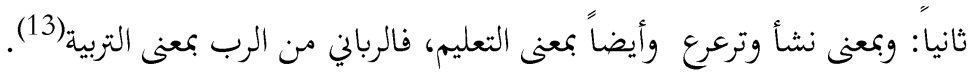

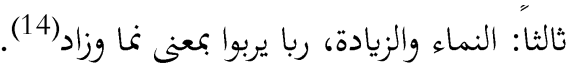

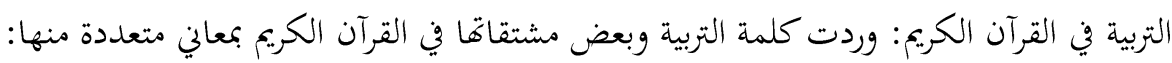

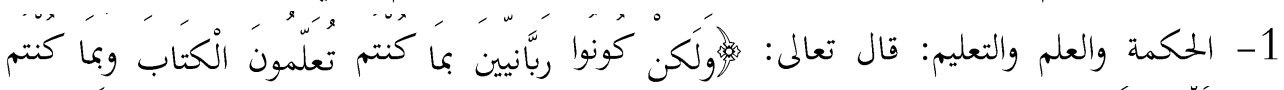

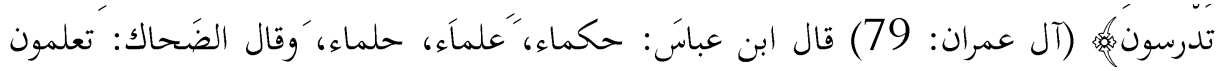
أي تفهمون(15).

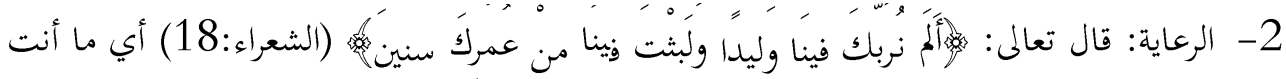

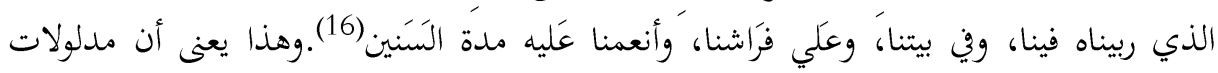

$$
\text { التربية هي الرعاية والعناية. }
$$

التربية بوجه عام في الاصطلاح: عبارة عن صقل ملكات الأفراد وتنمية مواهبهم وطاقاقم في جميع بجالات

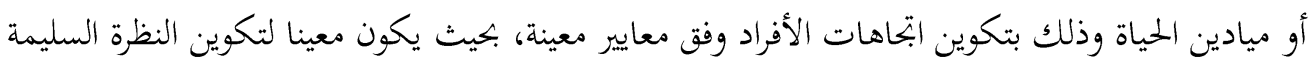

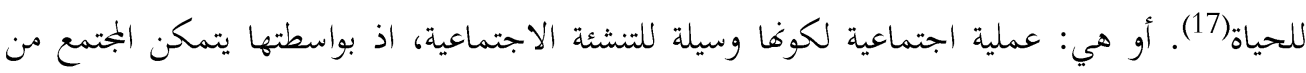
الحفاظ على تراثه الديني والثقافي والاجتماعي واستمراره، لأن في بقاء التراث بقاء المجتمع واستمراره(18). أما التربية الاسلامية: هي تنمية ملكات الفرد وقدراته على اختلافها من أجل بلوغ كماله بله العقلي والنفسي. وتنمية قدرات الجتمع كذلك من أجل تحقيق تطور أفضل، وتقدم اجتماعي أكمل. وفق المبادئ والقيم

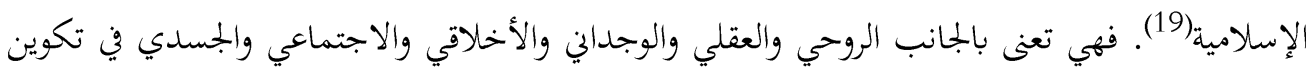


الشخصية الانسانية وفق معايير الاعتدال والاتزان، وترتكز على تنشئة الانسان الصالح بدون قيود الزمان والمان(المان

\section{الخور الأول: الحوار في سورة مريم}

يعتبر أسلوب الحوار في القرآن الكريم من أعظم الأساليب التربوية، ولم يقتصر القرآن على أسلوب حواري

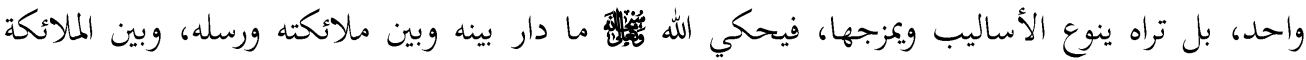
والرسل، وما دار بين الرسل وأقوامهم، وما بين البشر أنفسهم، وما بين الإنسان والحيوان كقصة سليمان

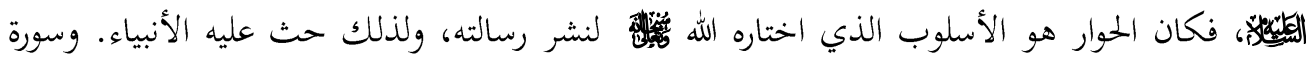
مريم من السور المفعمة بالحوار، أو بالأحرى بالقصص الحوارية. فمن مجموع (98) آية في سورة مريم (72) منها آيات حوارية (54) آية في القسم القصصي و (18) منها في الآيات غير القصصية، وهذه نسبة كبيرة

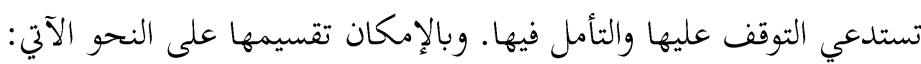
الأول: الحوار الوصفي التصويري: أسلوب قرآين يتم فيه عرض المشاهد الحوارية الواقعية بصورة حيَّة، ممًا

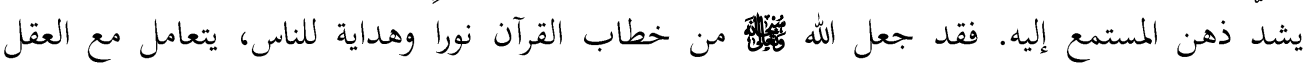

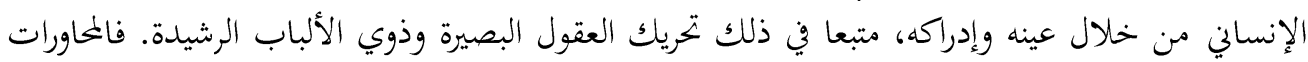
الواردة في القرآن الكريم محاورات فكرية هدفها نصرة الحق، واستعمال جميع طرق الإقنع وزوال الشك. فيك. (21).

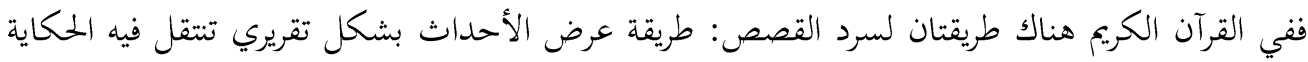

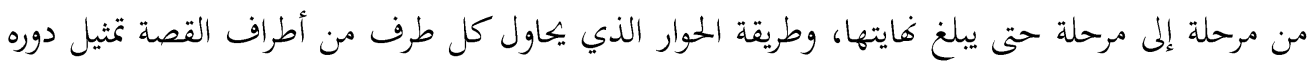

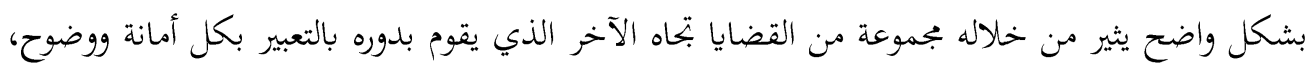

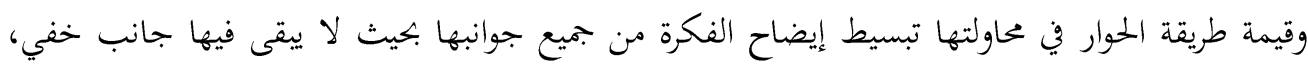

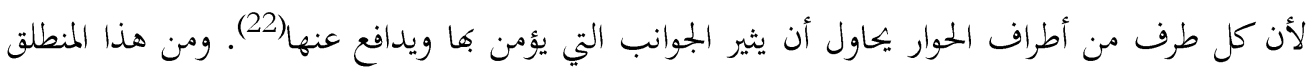
تنقسم الحوارات في السورة إلى قسمين:

أ- - الحوار الوصفي التصويري في الآيات القصصية: من ميزات القصص القرآي للأنبياء هي تلك الآثار

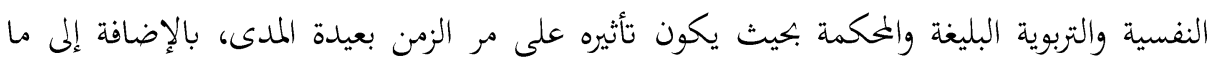
تثيره حرارة العاطفة وحيوية حركة النفس مما تدفع النفس الإنساني إلى تغيير سلوكه وتقوية عزيمته

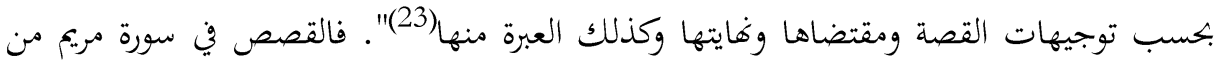

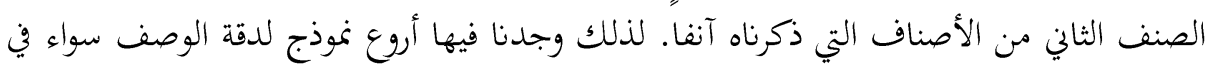

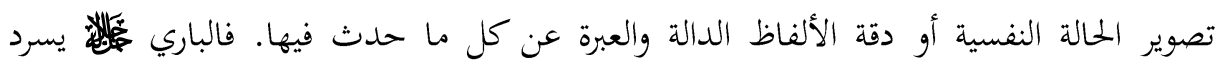




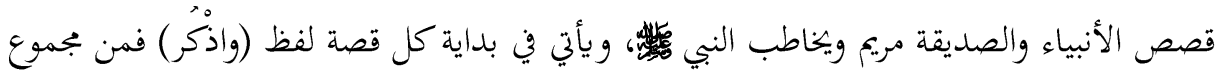

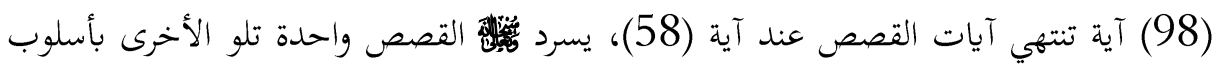

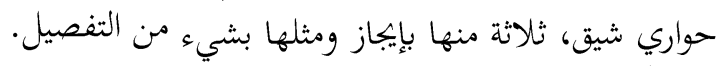

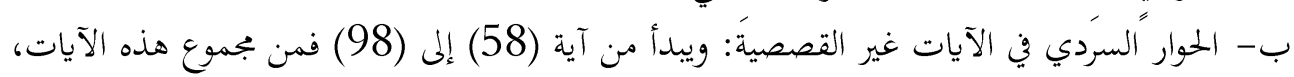

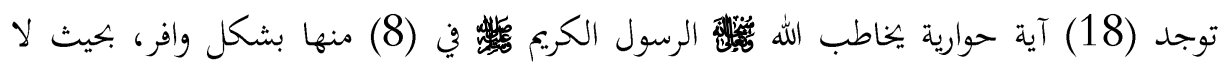
يقصد منه الرسول كشخص بقدر قصد الآيات بيان حال المعاندين.

\section{المعالم التزبوية المستفادة من الحوار الوصفي التصويري(24):}

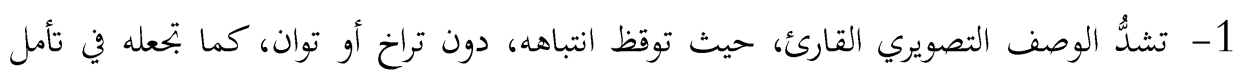
وتفكر دائمين لمعانيها والتبتع لمواقفها.

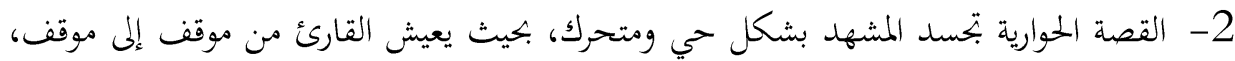

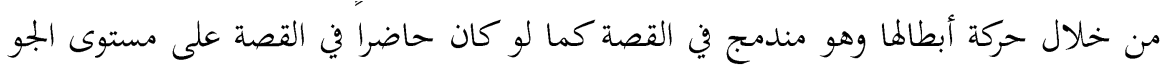
الذي يخيم على الموقف. 3- قد تكون بتحسيد الصورة الحقيقية المتحركة للتاريخ الرسالي من أسباب تركيز القرآن على الحوار

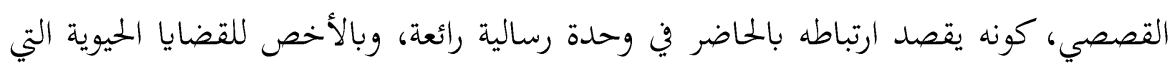
يريد القرآن إثاراها في حياة الناس وتعميمها في نفوسهم.

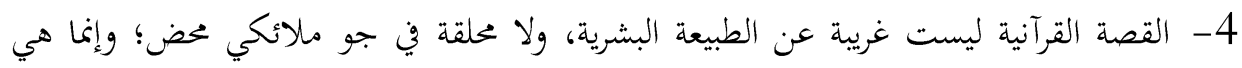

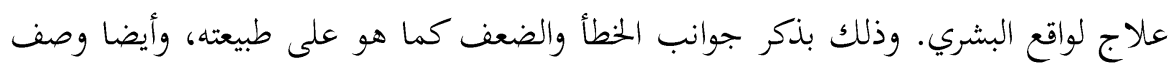

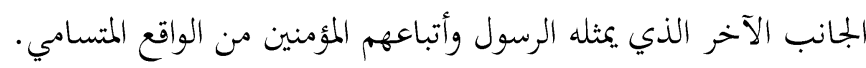

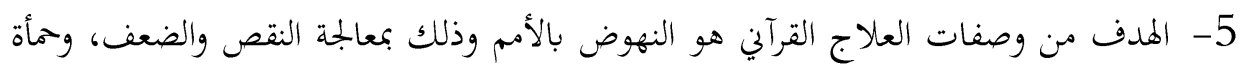

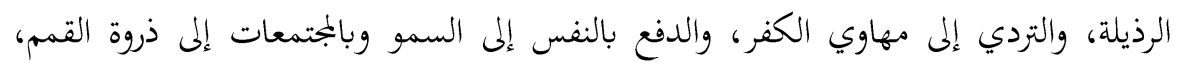
وذلك بوصفها في غهاية القصص انتصار الدعوة الإلهية وخسارة المعاندين المكابرين من المشركين.

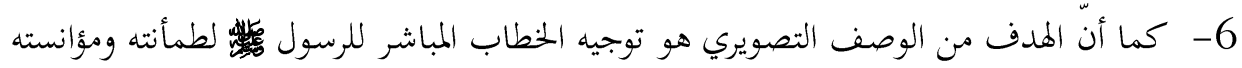

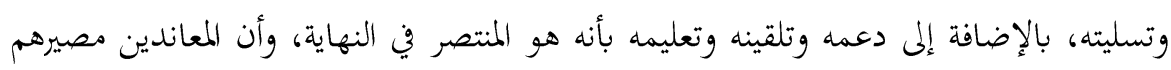
خسارة الدنيا والآخرة، لأنه كان في معركة دائمة معهمه.

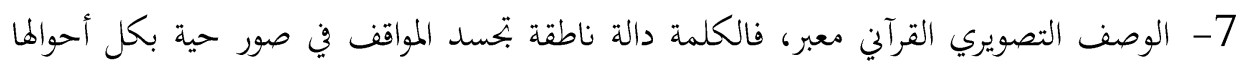

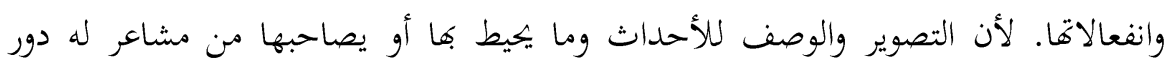


رئيس وفَّال في تبليغ الرسالة والفكرة المراد تبليغها، فالتصوير يمنح حركة للموضوع وينفخ فيه الحياة ليجعله صورة حية تتكلم أمامك.

الثاني: الحوار الثنائي: هو تبادل النقاش بين طرفين أو أكثر حول أمر معين، شرط وحدة الهدف والموضوع، وقد يصلان إلى نتيجة ما، وربما لا يتمكن أحدهما من إقناع الآخر، والسامع في النهاية

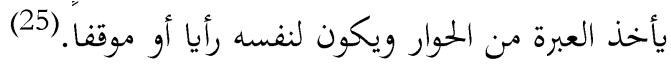
1- ويندرج تحت هذا القسم في سورة مريم عدة أنواع من الحوار: الحوار بين الخالق والمخلوق: وهو موإِ

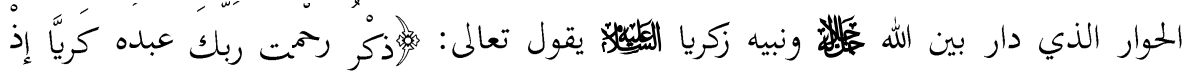

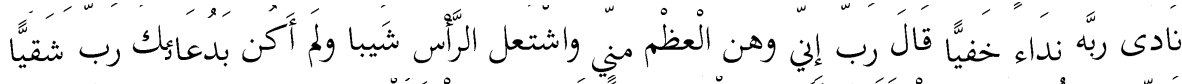

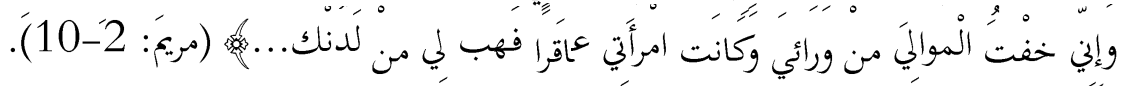

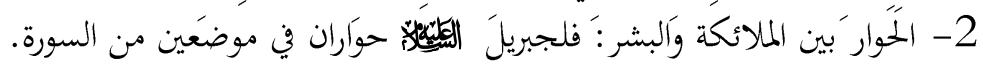

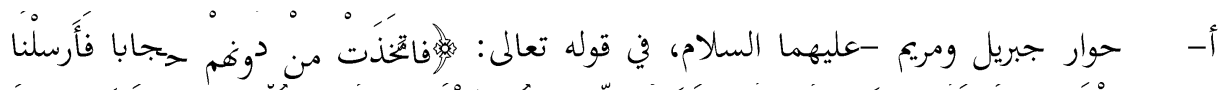

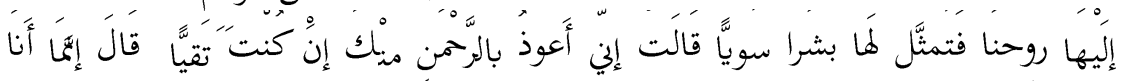

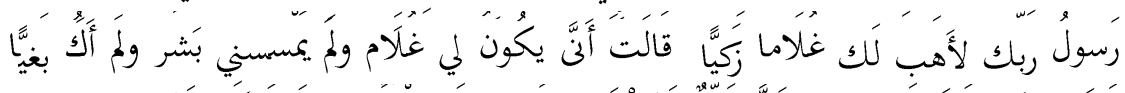

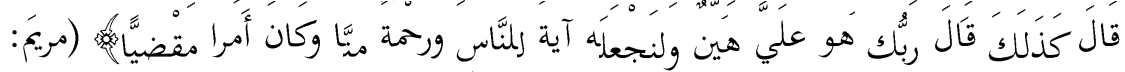
.(21-17

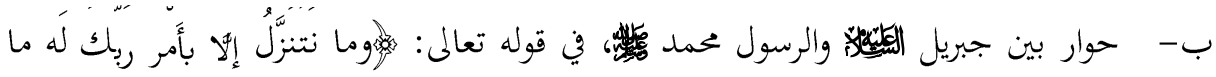

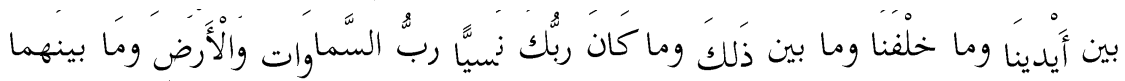

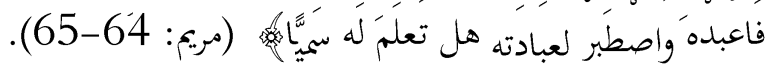

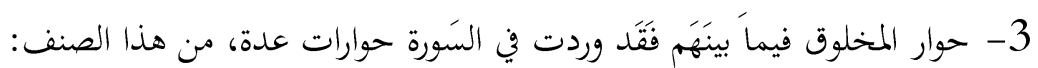

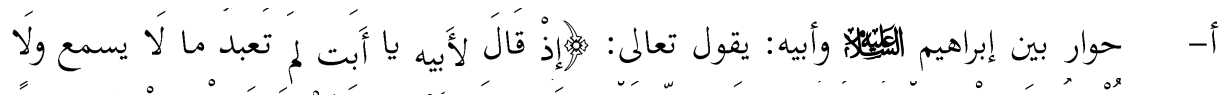

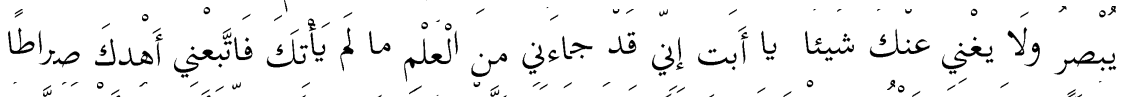

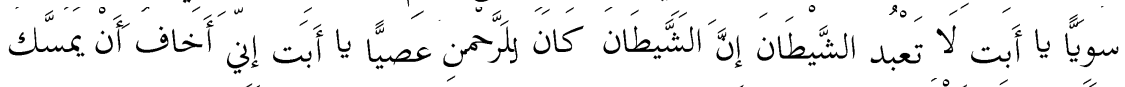

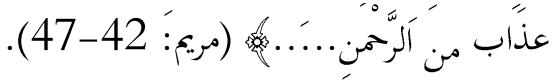

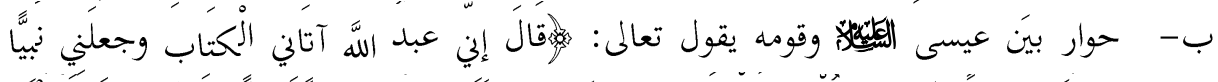

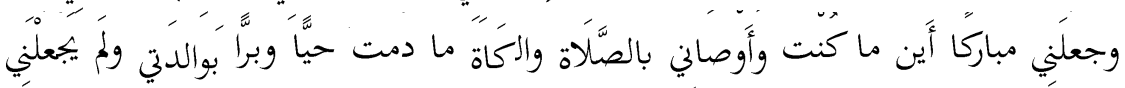

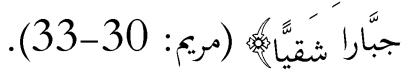




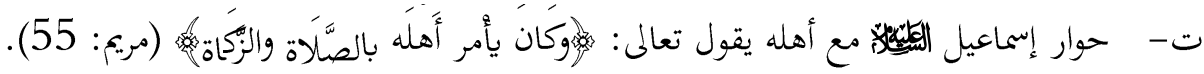

\section{المعالم المستفادة من الحوار الثنائي(26):}

1- الحوار بين الخالق والمخلوق مباشرة أو بواسطة الوسيط جبريل إنما هو خاصية انفرد بها الأنبياء تعظيما لقدرهم.

2- ما نلمسه في أدب زكريا في مخاطبة ربه، من التأدب بتنقية الألفاظ المهذبة وإظهار أقصى درجات

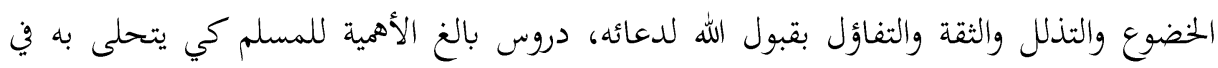
صالاته ودعاءه.

3- أما في حوار مريم وجبريل ينبغي إدراك أن الله هو الركن الركين والحصن الحصين في الملمات فيلزم اللجوء إليه.

4- - يفهم من فحوى الخطاب بين (جبريل ومريم) -عليهما السلام؛ أنه يلزم من الإنسان التقي أن ينأى بنفسه عن الشبهات، وأن يتقي بنفسه لكيلا يظن الناس به سوءا. فقد ورد أند أن رجلين من الأنصار

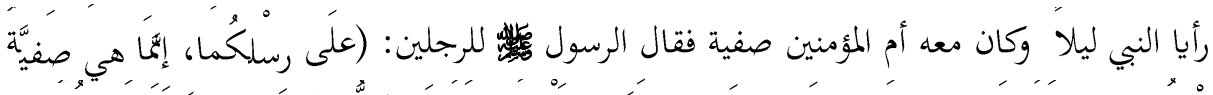

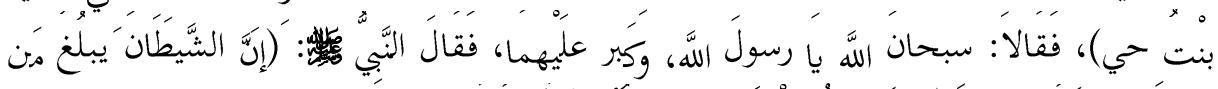

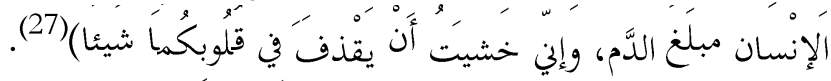

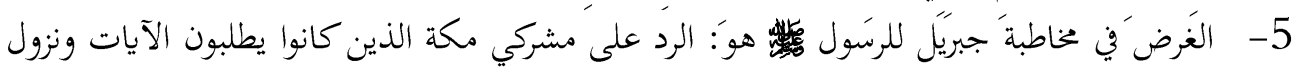

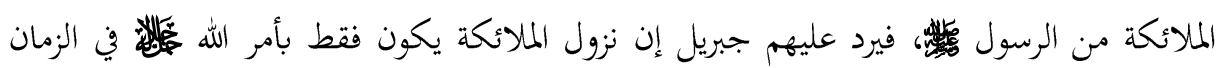
والمكان الذي يريده وليس على هوى المكابرين المعاندين. 6- طريق الدعوة إلى الله ليست مفروشة بالورود، بل تحتاج للصبر وتحمل مشاق الحياة. فقد تكون في مئي

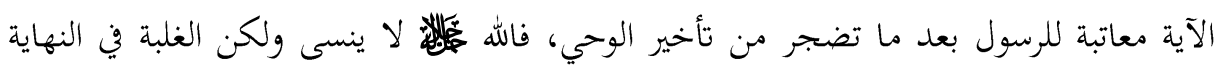
لمشيئته ولإرادته.

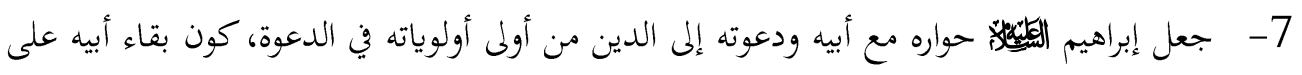

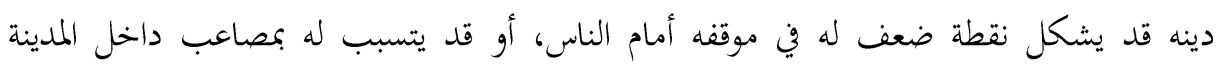
تجلب له المشاكل أو تعطل من خطواته. 8- إحدى أكبر الصعوبات التي واجهها إبراهيم اليلبله هي مواجهته لأبيه؛ كون المجتمع آنذاك يعطي

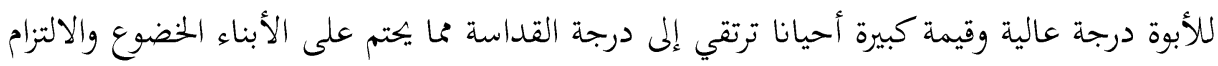


المطلق لهم، وهذا ما جعله شديد الحذر في أسلوبه، فعند التأمل في كلمات إبراهيم الئليّلِ لأبيه نلتمس منها شيئا من التوسل لأبيه، فهو في حالة من يخاطب أنسانا عزيزا معرضا للسقوط والهلاك.

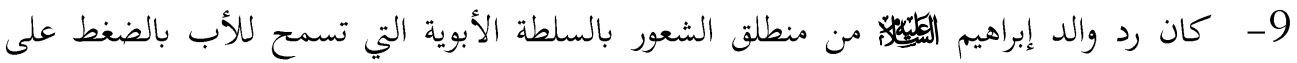
الابن، ليسير على خطى أبيه، وتهديده بالقوة والطرد والهجران إن خالف ذلك، فلا حوار في علاقتهما، إنما أمر وطاعة فلأب أن يعلن رغبته، وللابن أن ينفذ دون ترديد أو تفكير، إنها الشريعة السائدة آنذاك التي تحعل علاقة الآباء بأبنائهم علاقة تشبه بالعبودية.

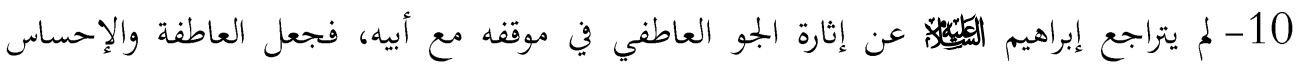

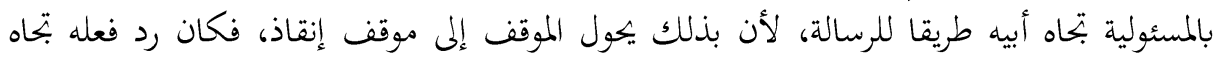
إنكار أبيه التوجه إليه بالسلام، والوعد بالدعاء له بالمغفرة بأن يوفقه لأسباهما بالهداية للإيمان. الثالث: الحوار غير المباشر: يتمثل الحوار غير المباشر في رد آيات القرآن الكريم على الأقاويل والكلمات التي يتداولها ألْنة بعضٍ ممن يختلفون مع عقيدة الإسلام، أو مع بعض جوازبها، أو أو علامات الاستفهام

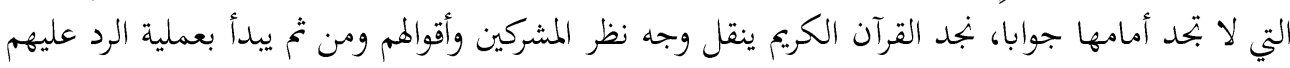

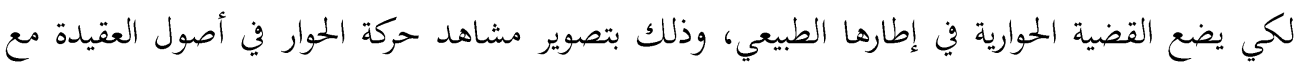
الملحدين ومنكري النبوة سواء من أهل الكتاب أو من غيرهم (28). ويستجلي ذلك في عدة مواضع مختلفة في سورة مريم وكالآتي:

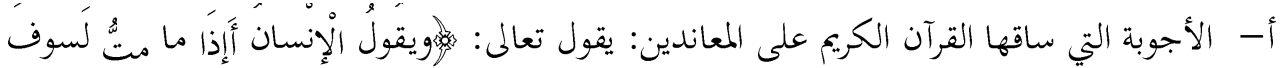

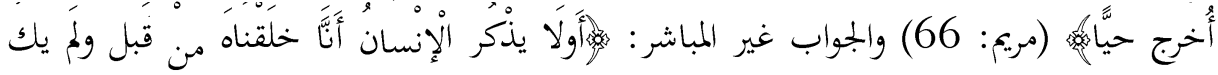
شيئايُه. (مريم: 67)، والآية هذه تدخل ضمن الحوار الحجاجي العقلي: وهو المفاوَضة على سبيل

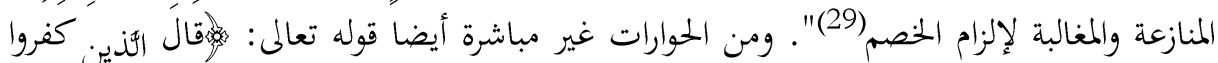

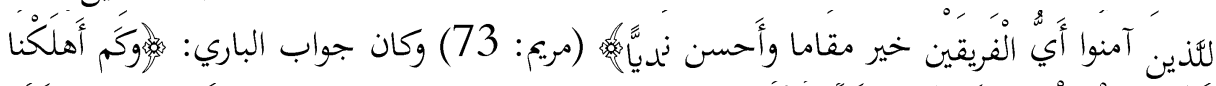

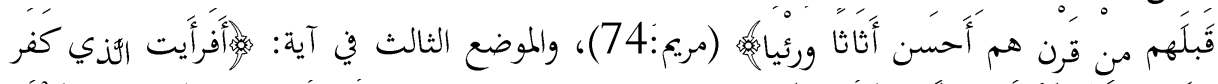

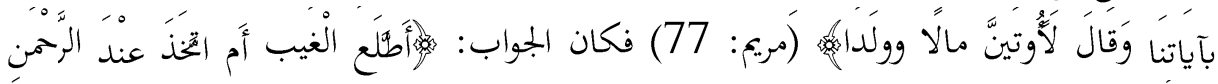

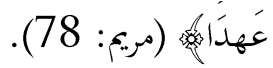

ب-حوار مريم بالإشارة مع قومها: ومن الحوارات غير المباشرة جواب الصديقة بالإشارة لقومها حينما

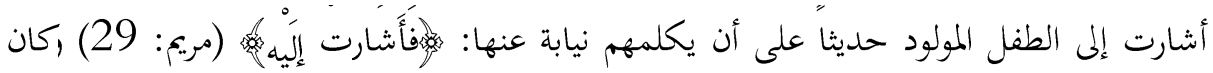

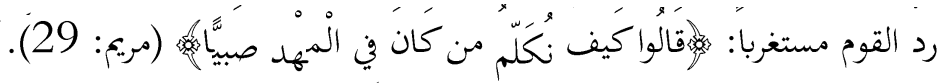




\section{المعالم التربوية المستفادة من الحوار غير مباشر.}

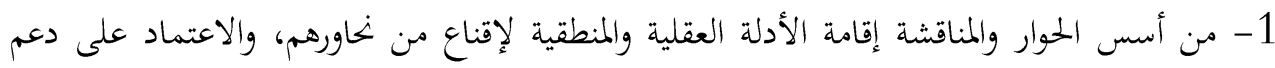
الحوار بالحجة القاطعة والبرهان اليقيني والتي يقصد منها دحض ادعاءات منكري البعث والتوحيد

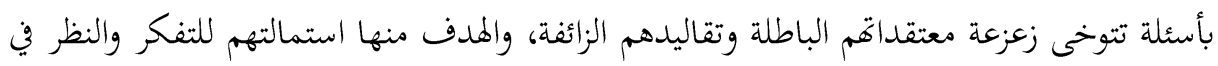
آيات الله لغرض اتخاذ مواقف صحيحة. وكذلك إطلاق التفكير وملكات العقل وإيقاظ الحواس

والأهم من ذلك التعامل الحي مع الطبيعة والحياة. (30)

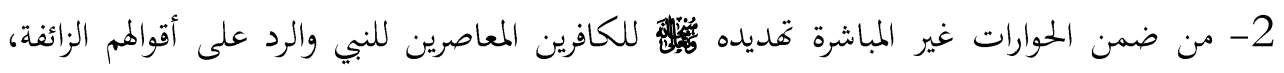

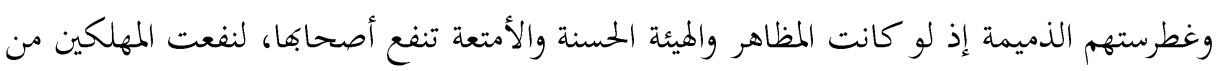

الأمم الغابرة. (31)

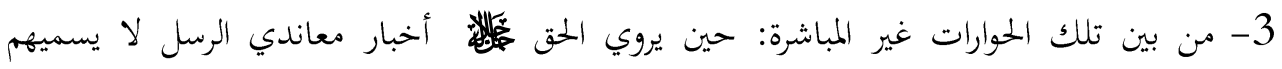

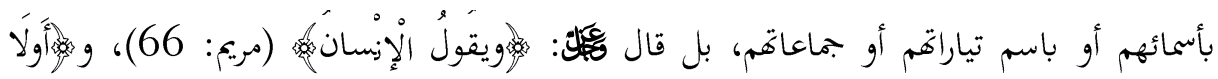

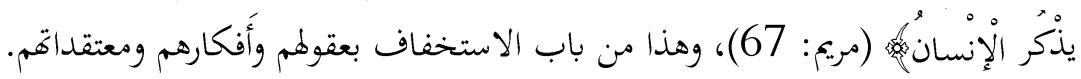

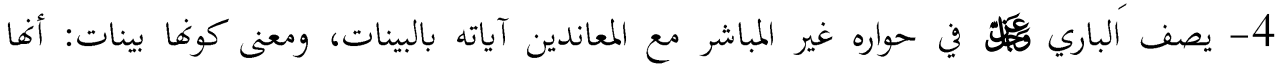

واضحات الحجة عليهم ومفعمة بالأدلة المقنعة.(32) 5- من جملة الحوارات غير المباشرة يطلب الله عز وجل من الرسول أن يرد على المتباهين بالأموال

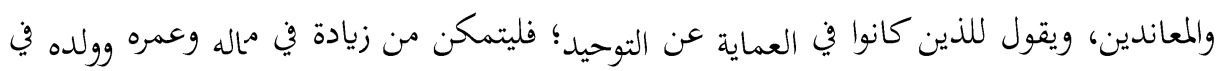

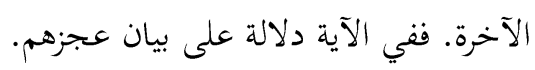

6- الصمت وعدم مجادلة ومحاورة السفهاء وفرت على الصديقة اللجاج والجدال، كونها أنثى ضعيفة

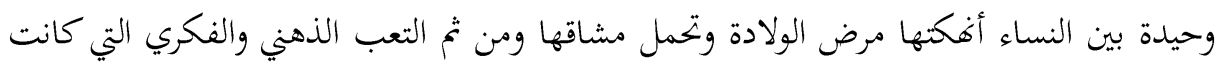
تراودها طول الوقت في كيفية مواجهة قومها وإثبات براءتا أمام الملأ.

الخور الثاين: أدب الخطاب والحوار في سورة مويم: جانب مهم في الحوار هو أدب الخطابة والتحدث، ولو قرأنا السورة بإمعان وتركيز شديدين لتبين لنا حيشية وكمية الأدب العالي والسلوك القويم أثناء التحاور والتخاطب، يا حبذا لو تمكن المؤمن من تطبيق والإلتزام بالآداب الخطابية والكلامية المستفادة من سورة مريم، حيث يجعل منه إنسانا في قمة رقيه الأخلاقي

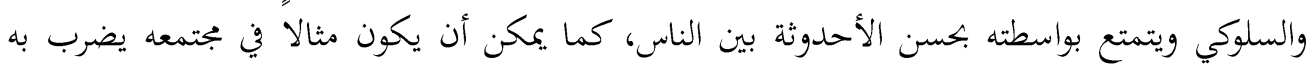


الأمثال، ناهيك عن رضوان الله تعالى عليه. وتتجلى تلك الآداب من الحوارات المذكورة للأنبياء في السورة وعلى النحو الآتي: (33)

1- النداء الخافت والغض من الصوت: فمن حسن الحوار غض الصوت ولين الككلام والوقار والسكينة

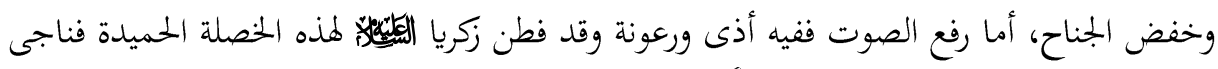

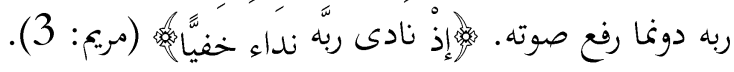

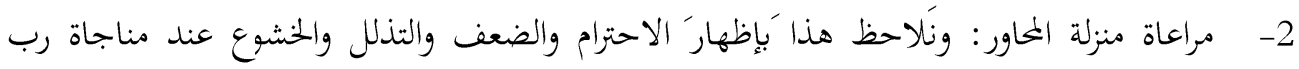

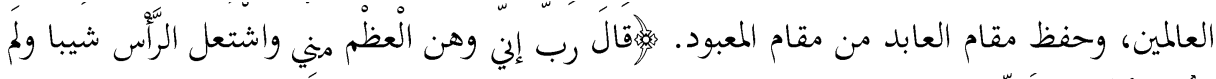

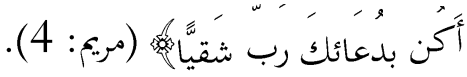
3- ذكر الَضضائل: فمَن البذور التي تزرع المحبة والتآلف بين المتحاورين إبشاره بما يسر به صدره وتقر به

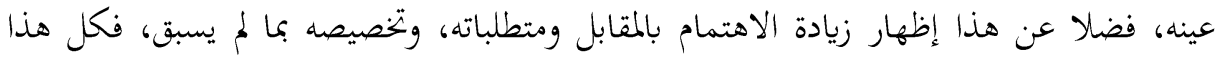

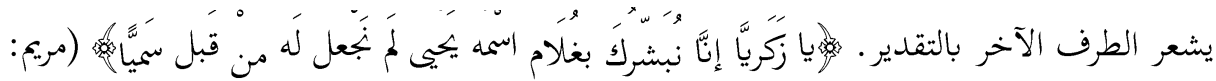

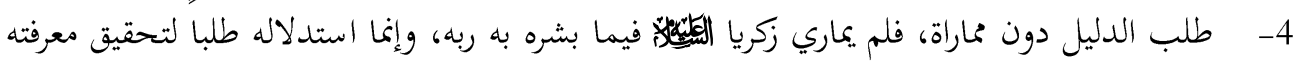

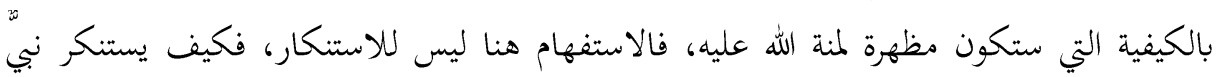

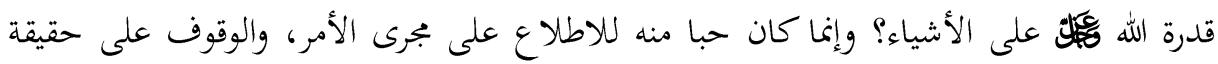

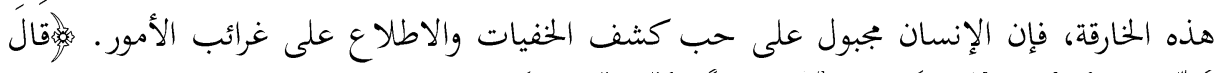

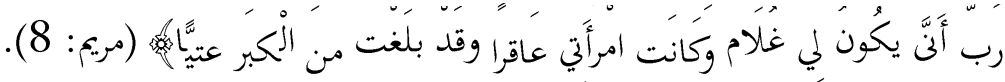

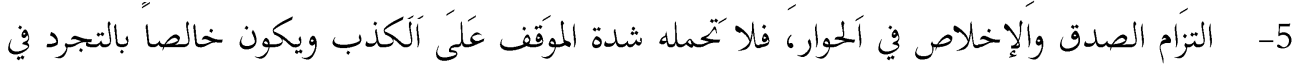
طلب حق من كل غرض دنيوي، فلا سمعه ولا جاه ولا مال، بل إخلاص الدعوة إليه، وإفراغ القلب

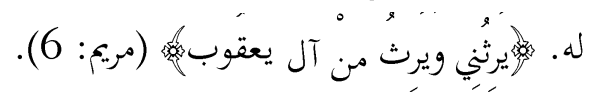

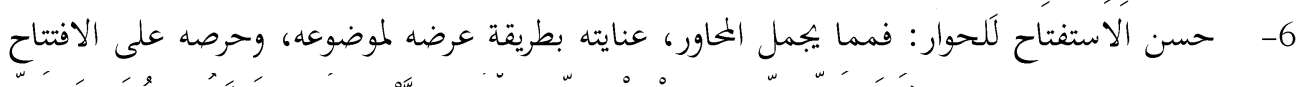

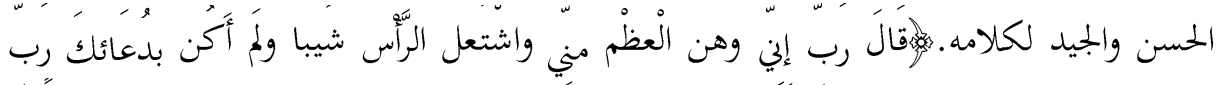

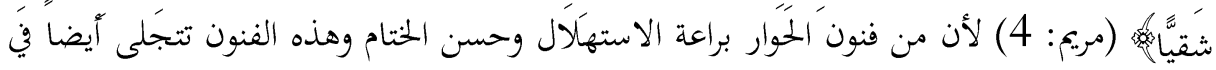
حوار إبراهيم الشيلنيل مع أبيه. 7- تعليل المطلوب والمراد وبيان مقاصده الحسنة: فسلامة النية خير معين على استجلاء الحقيقة.

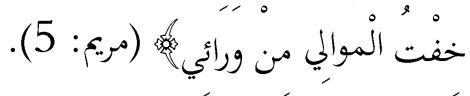


8- التعرف بالنفس: من الضروري أن يعرف كل شخص بكويته حتى يتمكن الطرف الآخر من تحديد

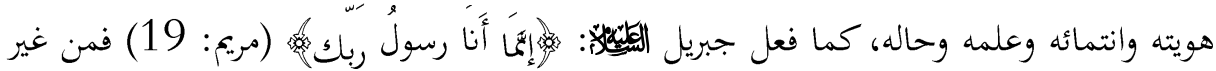
اللائق أن يتحاور الاثنان ويكون كل منهما مبهم للآخر.

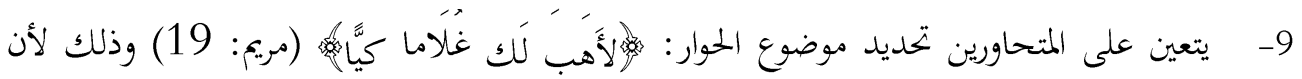

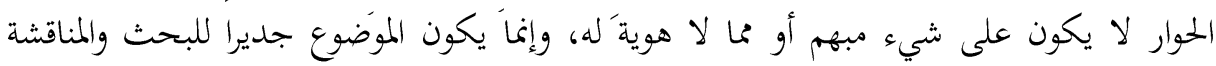
وتبادل الآراء. 10- هدوء النقاش بطيب الكلام دون افتعال الخصومة والنزاع، فحوار الصديقة مريم دارت في هدوء تام

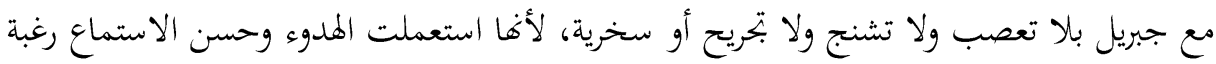
منها في الوصول إلى الحق.

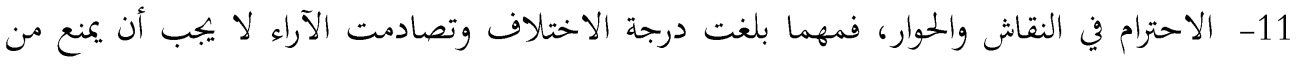

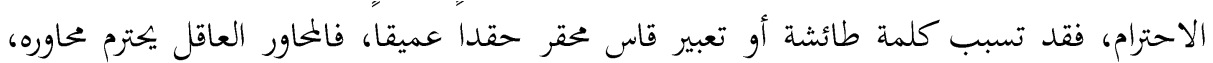
وهذا ما يتجلى في رد مريم لجبريل اللئليخ.

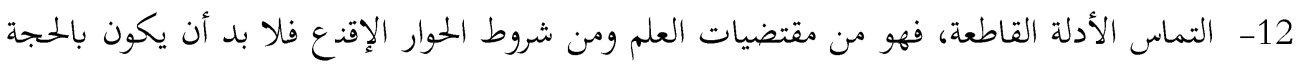

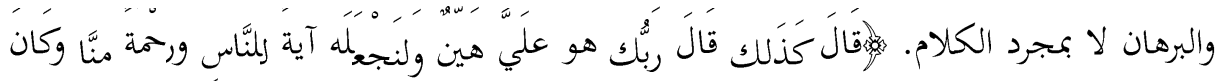

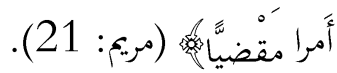

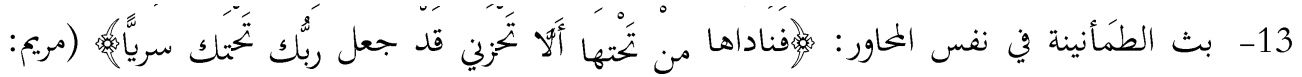
14- الامتناع والتحفظ عن مجادلة المتطفلين وعدم الدخول معهم في نقاشات دون فائدة. لوهأَشَارت

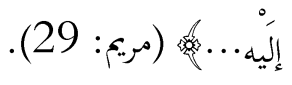

15- أتهَذب في الألفاظ، فالكلمة المهذبة تفتح مغاليق العقول والقلوب وتظهر حسن النية والحوار، كما

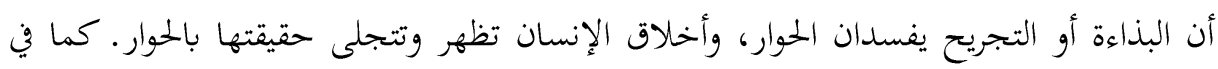
حوار إبراهيم اليليله مع أبيه. 16- التلطف والتحبب في الحوار يبعل له قيمته العالية، وبانعدامه تقلل الفائدة المرجوة، فثقافة الحوار

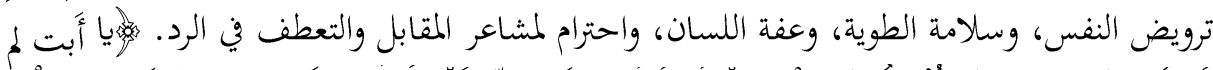

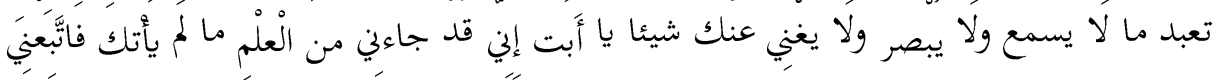




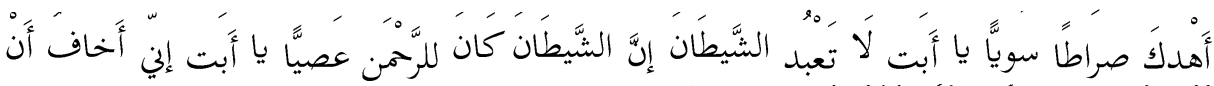

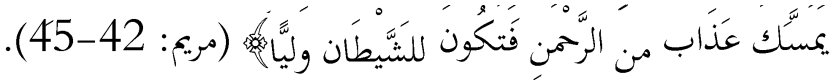

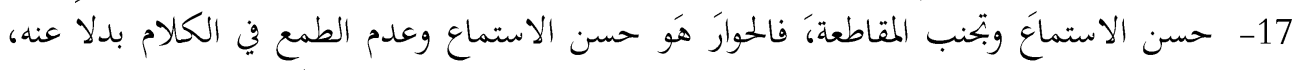

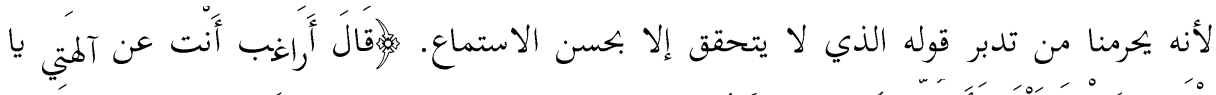

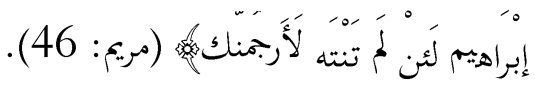

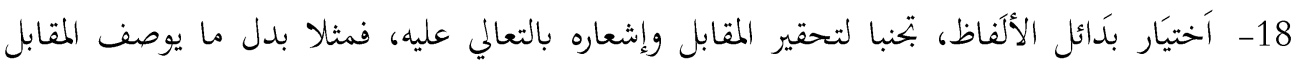

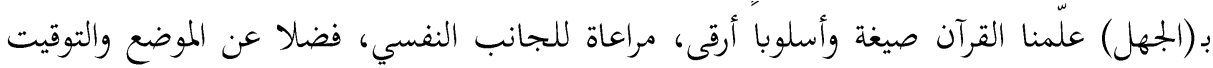

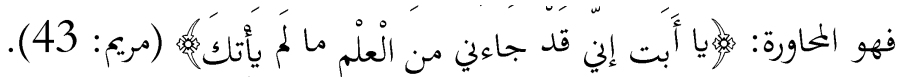

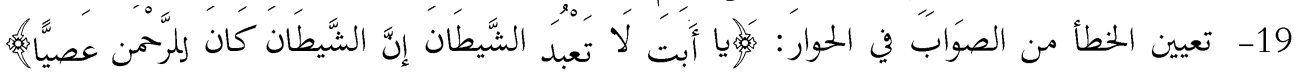

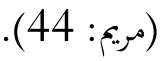

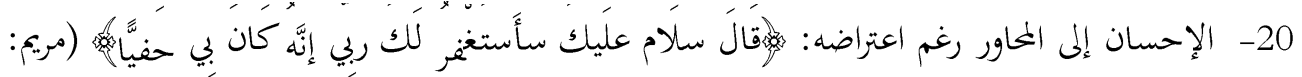

21- التدرج في الحوار إذ نلتمس التنوع في العرض، فمرة يكشف زيف معتقده، وأخرى يقرر له العقيدة الصحيحة، وثالثة يجذره من كيد الشيطان، ورابعه يجذره من غضب الرمان الدمن وعقابه.

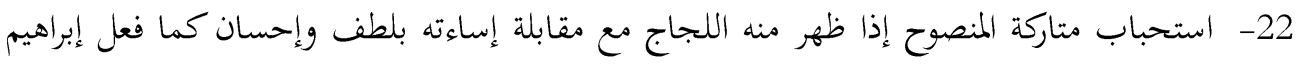

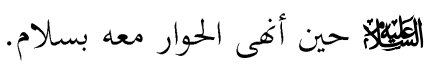

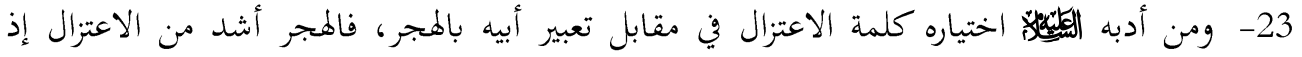

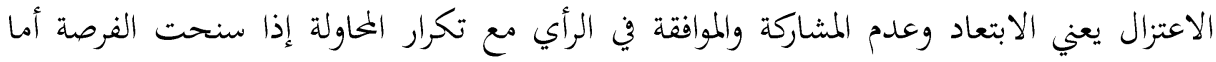
الهجر فيحمل معنى القطيعة والجفاء.

\section{الخهور الثالث: المعالم التربوية المستفادة من أسلوب الحوار وأدبه(34):}

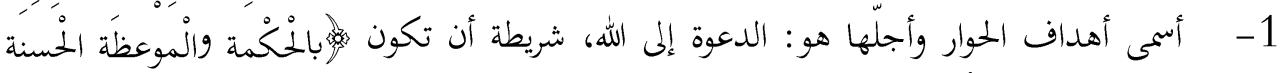

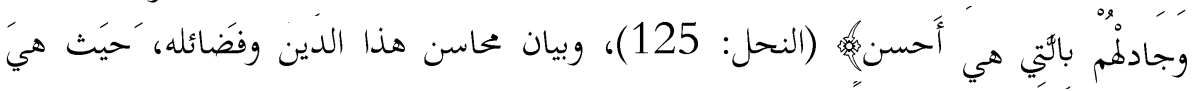
وظيفَة الأنبياء وآكرسل جميعا.

2- بالحوار يظهر الحق ويقام العدل، فليس المدف من الحن الحوار إقناع الطرف الآخر بقدر ما هو إظهار

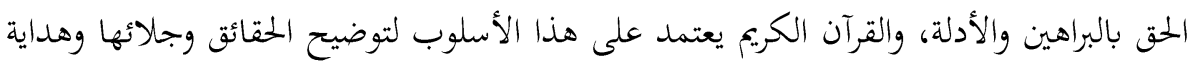
العقل وتريك الوجدان واستجاشة الضمير. 
3- بالحوار تنكشف سماحة الإسلام، وتظهر عظمة هذا الدين الرباني. فالإسلام لا يريد أن يفرض نفسه بالقوة والإكراه.

4- إن تعامل القصص الحواري القرآي مع النفس البشرية تتمثل في الواقعية الكاملة، وذلك عن الطريق

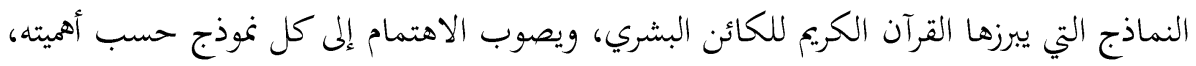
فيعرضها عرضا صادقا يليق بالمقام، بكيث يحقق الغاية والهدف التربوي.

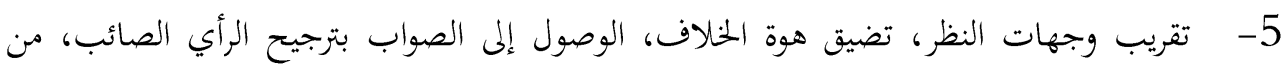

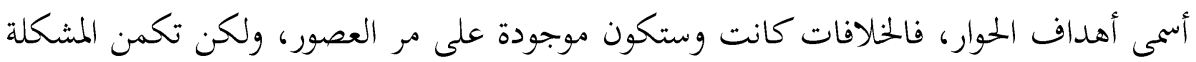
في ما يؤدي إليه الخلاف من تضارب وفرقة وتناحر وتباغض عندما يعجز المختلفون عن التفاهم

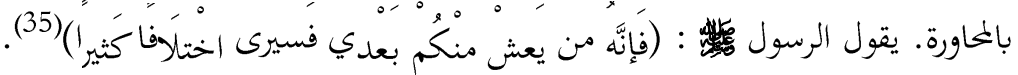

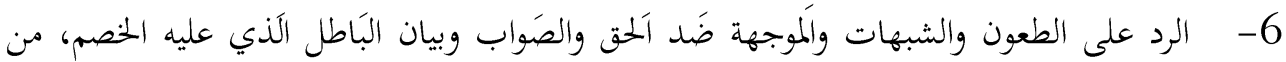
غايات الحوار، وذلك بإظهار الباطل على حقيقته، وإقامة الحجة على المخالف لكي يحذر منه الآخرون. 7- من الأهداف السامية والغايات الحميدة للحوار، الشفقة على الخصم، والخوف عليه من أن تتفرق به السبل، باعتباره إنسانا قامت عليه الحجة. 8- المحاور المسلم يستمد قوته من قوة الدين الذي يدين به، وعظمة الإيمان الذي يخالط قلبه، ومن

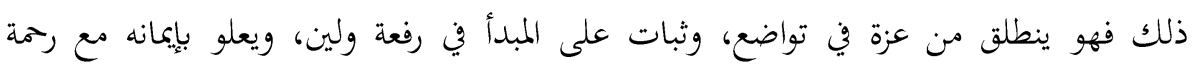
الآخرين، لذلك يحتاج المحاور على درجة من العزة واستعلاء الإيمان، مع الثبات على الحق، فلا يجبوز أن يؤدي الحوار بالمسلم إلى الذلة والمهانة أو يزعزعه عن الحقى المبين.

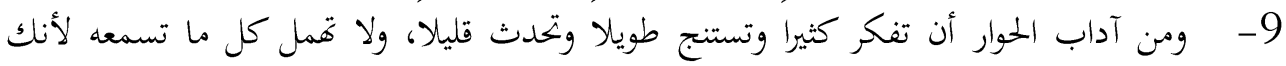
ستحتاجه في المستقبل. 10- على المحاور التواضع بالقول والفعل وعدم الترفع والتعالي على الخصم حتى لو كان أقل منك علماً، أو مالت كفة النقاش لصالحك، فمن تواضع لله رفعه، فتقدير الخصم واحترامه سلوك اسلامي.

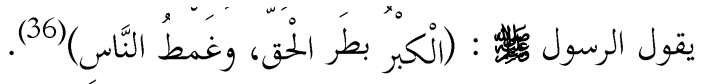

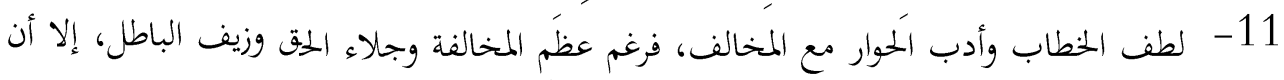

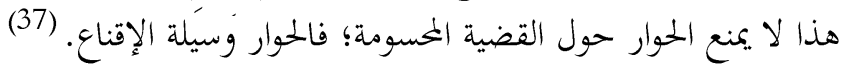


توصل الباحث بعد دراسته هذه إلى قناعة راسخة بأنه إذا ثبت هذا المبدأ المتين والرصين في المناهج التعليمية

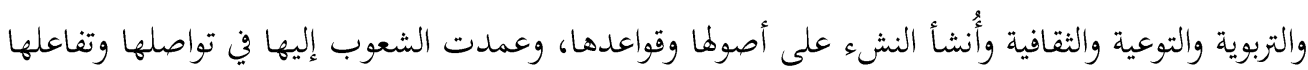
مع من يجيط بهم، يؤدي إلى جني هذه الثمرات:

1- الالتزام والتمسك بالحوار يؤدي إلى تغيير الكثير من الصراعات الموجودة اليوم، حيث تقل

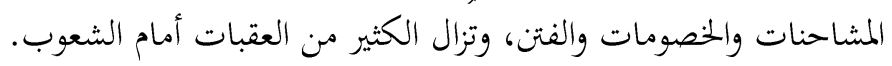

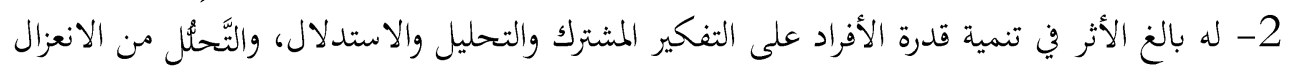
والانغلاق.

3- يمكن عن طريقه فتح قنوات التواصل التي يكتسب عن طريقها المزيد من المعرفة والوعي والتفكير

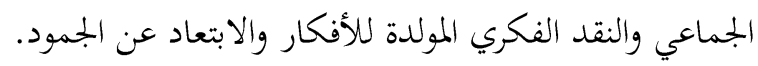

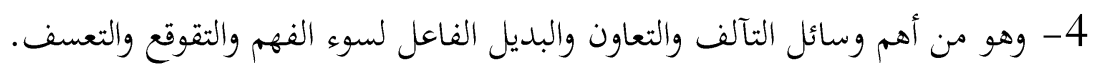

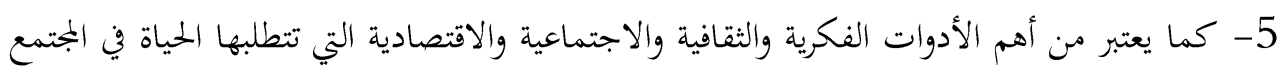
المعاصر . 6- هناك أساليب متنوعة وحوارات متعددة في سورة مريم، منها: الحوار الوصفي التصويري في الآيات القصصية، الحوار السردي في الآيات غير القصصية؛ الحوار الثنائي بين الله سبحانه وأنبيائه، بين

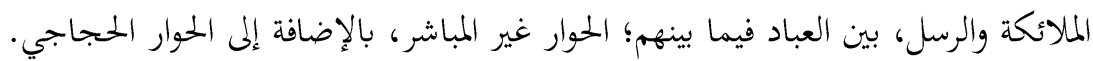

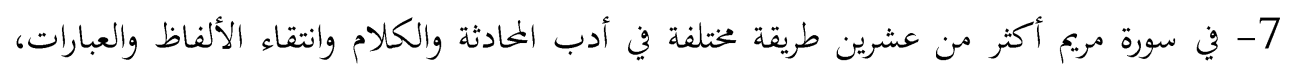

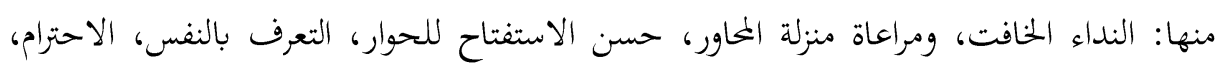
التهذب في الألفاظ، التلطف والتحبب، حسن الاستماع، بث الطمأنينة في نفس المحاور وغيرها. 8- في سورة مريم الكثير من المعالم التربوية المأخوذة من حواراها المختلفة، منها: إيقاظ انتباه المحاور

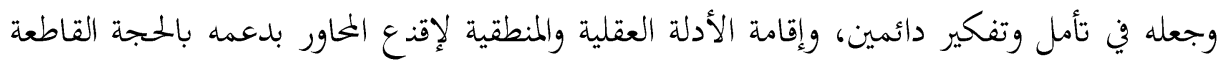

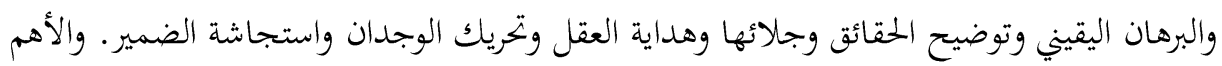
من كل ذلك تقريب وجهات النظر وتضيق هوة الخلاف والوصول إلى الصواب بترجيح الرأي

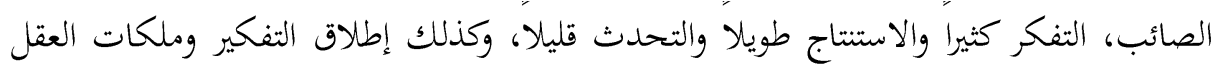
والتعامل الحي مع الطبيعة والحياة. 
ابن كثير، أبو الفداء إسماعيل بن عمر بن كثير القرشي، تفسير القرآن العظيه، تحقيق: سامي بن محمد سلامة، ط2، دار طيبة للنشر والتوزيع، 1420هـ-

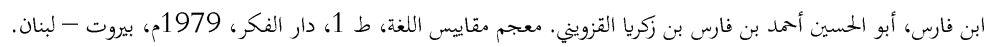
.2

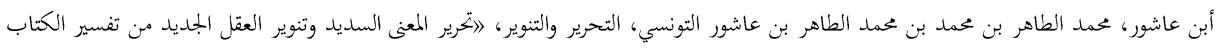

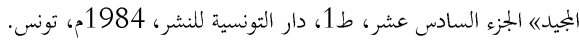

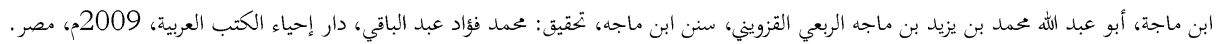

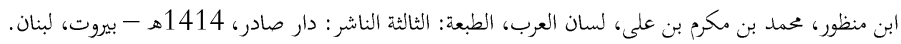

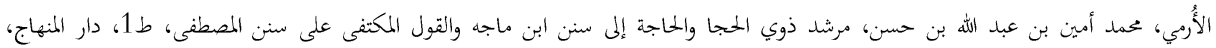

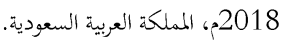

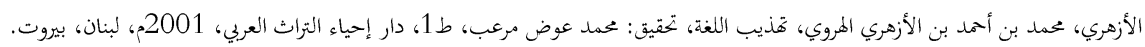

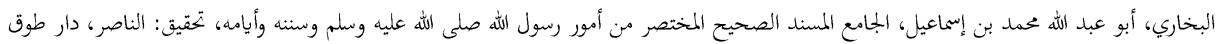
.7 النجاة، 1422هـ، بيروت، لبنان.

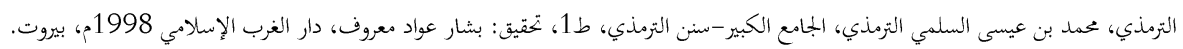

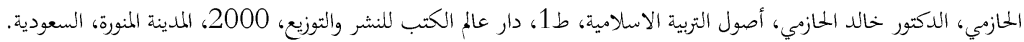

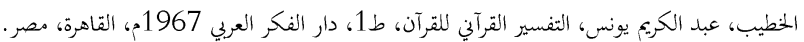
.4 .5 .6

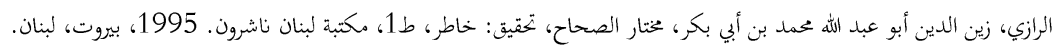

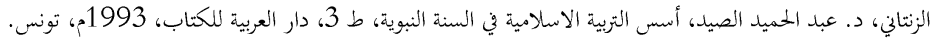
.12

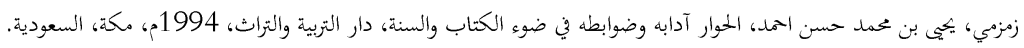

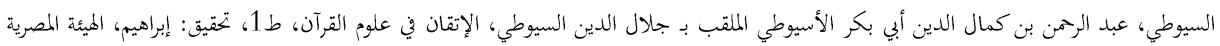

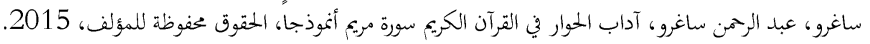

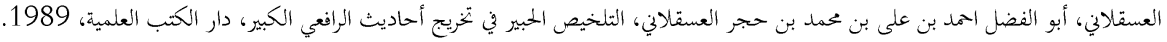

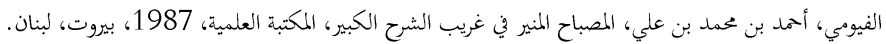

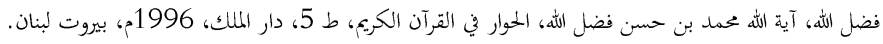

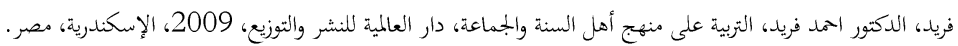

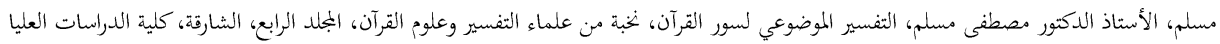

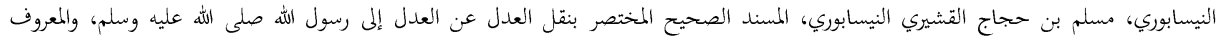

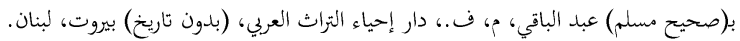

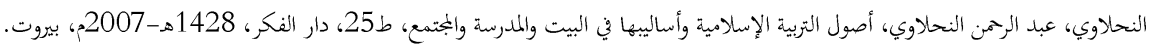

$$
\begin{aligned}
& \text { (1) النورسي، سعيد النورسي ، الكلمات، ص } 430 . \\
& \text { (2) الحازمي، أصول التربية الاسلامية، ص375. }
\end{aligned}
$$

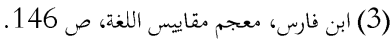

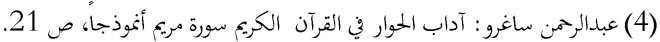

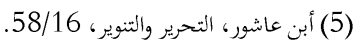




$$
\begin{aligned}
& \text { (6) الدكتور مصطفى مسلم، التفسير الموضوعي لسور القرآن،403/4. }
\end{aligned}
$$

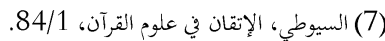

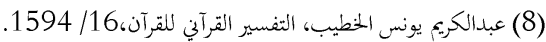

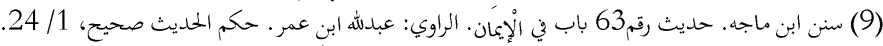

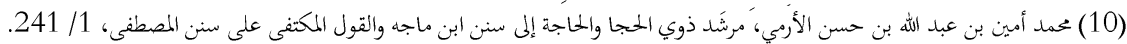

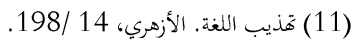

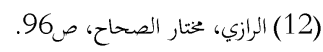

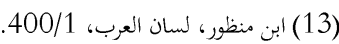

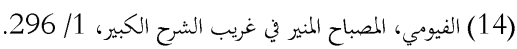

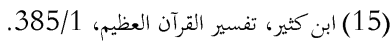

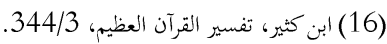

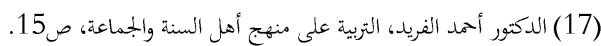

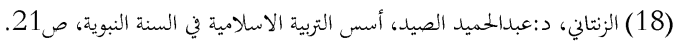

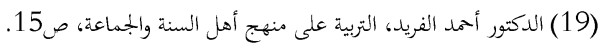

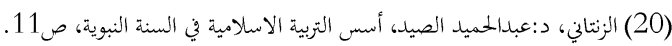

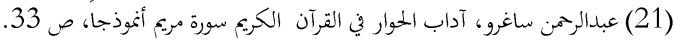

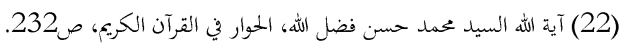

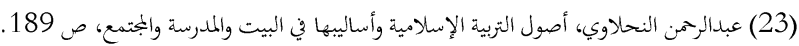

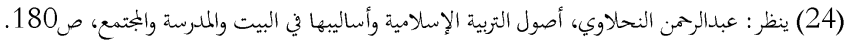

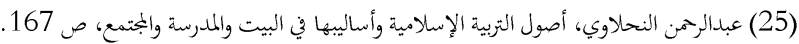

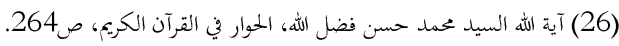

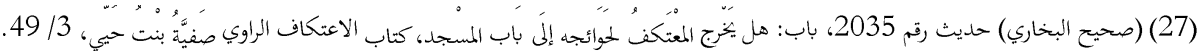

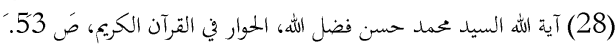

$$
\text { (30) (39) المصدر نفسه، ص63. }
$$

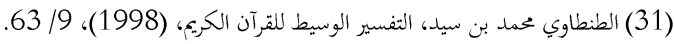

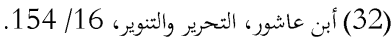

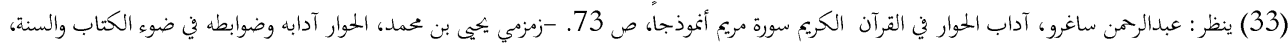

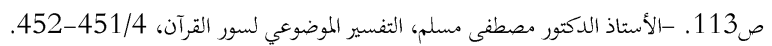

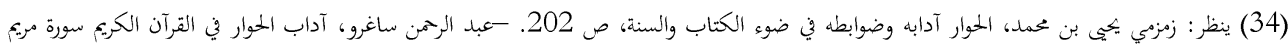

أنموذجا، ص 63.

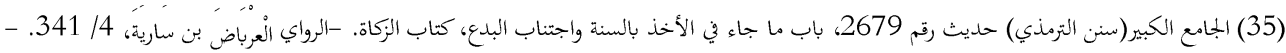

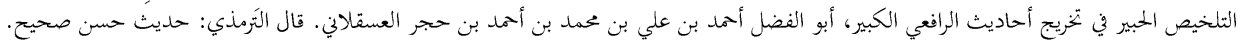

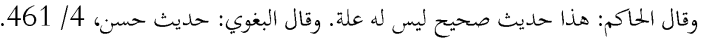

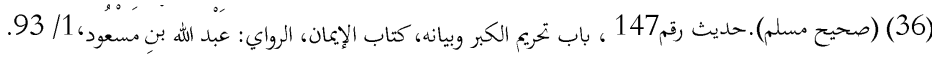

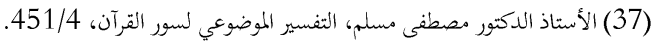

